RESEARCH ETHICS

\title{
Applying a research ethics committee approach to a medical practice controversy: the case of the selective COX-2 inhibitor rofecoxib
}

\author{
M J James, L G Cleland
}

J Med Ethics 2004;30:182-184. doi: 10.1136/jme.2003.004515

\begin{abstract}
See end of article for authors' affiliations

....................

Correspondence to: M J James, Rheumatology Unit, Royal Adelaide Hospital, North Terrace, Adelaide, SA, Australia 5000; michael.james@ adelaide.edu.au

Revised version received 2 November 2003 Accepted for publication 6 November 2003
\end{abstract}

\begin{abstract}
The new class of anti-inflammatory drugs, the COX-2 inhibitors, have been commercially successful to the point of market dominance within a short time of their launch. They attract a price premium on the basis that they are associated with fewer adverse gastric events than traditional anti-inflammatory drugs. This marketing continues even though a pivotal safety study with one of the COX-2 inhibitors, rofecoxib, showed a significant increase in myocardial infarction with rofecoxib use compared with a traditional antiinflammatory drug. This finding has led to a series of publications containing pooled analyses of existing data that both support and refute the possibility of increased cardiovascular risk with COX-2 inhibitors. These medical journal publications have served to obfuscate rather than provide guidance for medical practitioners. Consideration of a research ethics committee approach to this issue suggests that it would deal with the controversy in a straightforward manner-namely, it would simply inform research participants of the trial results with rofecoxib. The certainty of this research ethics committee approach raises the issue of whether it should be applied in normal medical practice outside of the research environment. A consideration of the legal tests for disclosure of information suggests that therapeutic medical practice should mirror that within the research environment, in this case.
\end{abstract}

$\mathrm{T}$ raditional non-steroidal anti-inflammatory drugs (NSAIDs) decrease the pain and swelling associated with inflammatory conditions, such as rheumatoid arthritis; however, their chronic use increases the risk of severe gastric side effects, including haemorrhage. The new class of anti-inflammatory drugs known as cyclooxygenase (COX)-2 inhibitors were developed with the aim of decreasing the pain and swelling of inflammation without the increased risk of adverse gastric events.

The first drug in this class was celecoxib, marketed by GD Searle \& Co as Celebrex. Celebrex had total sales of US $\$ 1.5$ billion in 1999, its first year on the market, and it was the most successful drug launch in US history. The second drug in this class was rofecoxib, marketed by Merck \& Co as Vioxx. Vioxx had total sales of US $\$ 2.5$ billion in 2001 and is the most prescribed arthritis pain medication across Europe, Canada, and Latin America. ${ }^{1}$

Although this is a successful outcome for the pharmaceutical companies involved, it has been argued that there should be caution in the prescription of new drugs because of limited information about their effectiveness, safety, and whether they offer an overall advantage over existing medications. ${ }^{2}$ It has also been argued that strong marketing of new drugs can give impetus to their prescribing when there is doubt over their usefulness or safety. ${ }^{2}$ Rofecoxib prescribing provides an example of this principle, with over one million samples given to Canadian doctors in the year 2000. This is more samples than any other product and is only slightly ahead of the second ranked product, celecoxib, with slightly fewer than one million samples provided to doctors in the same year. ${ }^{3}$ In addition, the number of "detailing" visits by pharmaceutical representatives to Canadian doctors in 2000 to promote celecoxib and rofecoxib were 77,000 and 48,000 , respectively. ${ }^{3}$ Given this marketing impetus, it is important to consider how controversies over new drugs such as COX-2 inhibitors can be handled by prescribing doctors.

\section{THE MEDICAL CONTROVERSY: ADVERSE CARDIOVASCULAR EVENTS IN A VIOXX TRIAL}

Merck funded a clinical trial in a large group of rheumatoid arthritis patients with the aim of examining the gastric safety of rofecoxib. This was the VIGOR study and initial publication of results indicated an unequivocal advantage of rofecoxib over a traditional NSAID (naproxen) for serious adverse gastric events. ${ }^{4}$ However, this publication mentioned also a greater incidence of myocardial infarction in the rofecoxib group. This result was framed in terms of a protective effect of naproxen rather than an adverse effect of rofecoxib. ${ }^{4}$ Although not published by Merck, availability of the complete VIGOR data set became available on the US Food and Drug Administration (FDA) website along with the US FDA review. This review revealed the significant increases in serious thrombotic cardiovascular events in the rofecoxib group versus the naproxen group. ${ }^{5}$ The effect appeared at 3 months and became especially marked by 8 months of treatment on trial.

Such a result suggested that the cardiovascular disadvantage of rofecoxib use may outweigh the gastric advantage. There followed a series of publications with analyses of existing data, which both supported and refuted the findings of cardiac risk in the VIGOR study. These included in succession:

- Mukherjee et al compared myocardial infarction rates from already published studies with the COX-2 inhibitors, celecoxib and rofecoxib, with the placebo group of a published meta-analysis and concluded that use of COX-2 inhibitors was associated with increased risk of adverse cardiovascular events. ${ }^{6}$

- then, investigators from Merck and two medical centres reported a pooled analysis of a large number of studies with rofecoxib. This analysis pooled data, presumably held on file by Merck, from studies with 4 weeks' exposure to 
approximately 2 years' exposure and concluded there was no increased thrombotic risk from rofecoxib use compared with placebo or non-naproxen NSAIDs. ${ }^{7}$

- Ray et al, using data from the Tennessee Medicaid program, reported that naproxen was not protective for serious cardiovascular disease ${ }^{8}$ and that rofecoxib at doses $>25 \mathrm{mg}$ significantly increased the risk for serious cardiovascular disease in a group with mean rofecoxib use of 6 weeks. ${ }^{9}$

- in a commentary article, Hochberg urged medical practitioners to "be strong and resolute" and continue to prescribe COX-2 inhibitors. ${ }^{10}$

Thus, the findings of cardiac risk in the VIGOR study have been vigorously contested, using mainly statistically complex analyses of existing data sets.

\section{BIOLOGICAL PLAUSIBILITY FOR ADVERSE CARDIOVASCULAR EFFECTS OF COX-2 INHIBITORS} During the statistical disputes over the findings of cardiac risk in the VIGOR study, cellular and animal studies revealed potential mechanisms for acceleration of occlusive vascular disease arising from selective COX-2 inhibition. Collectively, these studies have shown that:

- upregulation of endothelial COX-2 and consequent production of prostacyclin, an antithrombotic prostaglandin, may be a protective homeostatic response of blood vessels to platelet activation ${ }^{11}{ }^{12}$

- ingestion of celecoxib or rofecoxib by healthy volunteers inhibited prostacyclin production ${ }^{13} 14$

- the intimal hyperplastic response to vascular injury in mice is suppressed by prostacyclin - a product of vascular COX-2 activity. ${ }^{15}$

Collectively, these studies provide potential mechanisms whereby selective COX-2 inhibition could unbalance the homeostatic responses of the vessel wall to injury and to thrombus formation. Thus, there is biological plausibility for the increased occurrence of occlusive cardiovascular events with rofecoxib use in the VIGOR study. It is unlikely, however, that busy medical practitioners will be exposed to these results, which were published in the basic science literature, and even if they were aware of the results a practice dilemma would still emerge after attempting to balance all of the arguments.

\section{GUIDANCE FOR PRESCRIBING WILL NOT COME FROM EXISTING DATA}

When recent medical journal publications both support and refute arguments for increased cardiovascular risk attached to use of COX-2 inhibitors, confusion and indecision for medical practitioners is understandable. The medical journal publications have served mainly to highlight the myriad analytical alternatives available to researchers, including those within the pharmaceutical industry. The overall result is to provide only obfuscation for prescribing doctors.

Thus, despite the statistically significant finding of increased myocardial infarction in a definitive trial with Vioxx, and despite the emergence of biological plausibility for the adverse cardiovascular events, the sales of Vioxx have continued unabated, with Merck's estimate for 2003 being US\$2.6 billion. ${ }^{1}$

As outlined above, there are considerable existing data on COX-2 inhibition, vascular homeostasis, and clinical events. The significance and meaning of individual findings is, however, disputed by the various stakeholders. Given this situation, guidance for prescribing practitioners is unlikely to come from further analysis of existing data. We suggest that an immediate solution for practitioners is provided by considering the problem in a different framework-namely, the ethical/legal framework surrounding duty of care. The impetus for this approach arises from considering how the controversy would be handled in a research environment.

\section{A RESEARCH ETHICS COMMITTEE APPROACH}

If a research ethics committee (REC) were considering an application that involved the use of rofecoxib, there is no doubt that participants would be informed that there was an increased incidence of myocardial infarction in a previous trial with this drug. In the participant information sheets for clinical drug trials, the lists of potential adverse events arising from registered or experimental drugs are large and they attempt to be exhaustive. In some cases, particularly those involving cancer trials where several drugs are used in combination, the information sheets can be $8-10$ pages in length; in part, this is because of the attempts to be exhaustive in listing potential drug side effects. Although we acknowledge that such lists are so voluminous that they become uninformative, there is a perceived obligation to list all possible adverse events. This general consideration makes the specific point that, in the case of rofecoxib, there can be no doubt that an increased risk of myocardial infarction would be listed in a clinical trial information sheet as a possibility.

\section{DUTY OF CARE IN THERAPEUTIC PRACTICE}

The ethics committee approach may seem extreme with regard to everyday medical practice, where the provision of information by the practitioner on potential drug adverse side effects is unlikely to be exhaustive. It is valuable, however, in raising the question of whether there is a duty of care for medical practitioners to inform patients given a prescription for rofecoxib, that there was an increased rate of myocardial infarction with its use in the VIGOR study. What should be the test to determine this?

The scope of the duty of care in the provision of information for treatment is not readily discerned, particularly in the absence of legal training. It is clear, however, that failure to warn of risks comes under the legal action of negligence. In the past, the "Bolam principle" has been used extensively to test this. In Sidaway $v$ Governors of Bethlem Royal Hospital (1985; AC 871), Lord Scarman stated:

The Bolam principle may be formulated as a rule that a doctor is not negligent if he acts in accordance with a practice accepted at the time as proper by a responsible body of medical opinion ...16

According to this test, not informing a patient of the VIGOR results on myocardial infarction is unlikely to be negligent because this is probably the accepted practice of a great many responsible medical practitioners. This is likely to be the current situation either because doctors are unaware of these results or because the published information on VIGOR is contested to the point of obfuscation. Under the Bolam test, it is probably reasonable for a medical practitioner not to disclose this information.

However, the High Court of Australia set a different test in Rogers $v$ Whittaker (1992; 175 CLR 479). The judgment stated:

The law should recognise that a doctor has a duty to warn a patient of a material risk inherent in the proposed treatment; a risk is material if, in the circumstances of the particular case, a reasonable person in the patient's position, if warned of the risk, would be likely to attach significance to it ... ${ }^{17}$

It can be assumed that most patients are likely to attach significance to the information that rofecoxib use was 
associated with a greatly increased incidence of myocardial infarction in a clinical trial. It is reasonable to assume that this information would be material to their decision as to whether they wanted to use rofecoxib as an anti-inflammatory agent when other options are generally available. Therefore, under the test imposed by the Rogers $v$ Whittaker judgement, a doctor would be negligent in not disclosing this information.

A prescribing doctor would need to provide this information in the context of other potential risks and benefits and in dialogue with the patient to ensure that their understanding and expectations are considered. With rofecoxib, the potential benefits may include decreased probability of serious gastric adverse events. ${ }^{4}$ If the patient had been taking a traditional NSAID without any serious gastric problems, however, then there would be no apparent advantage in changing to rofecoxib, particularly if there were no risk factors such as age and long term daily requirements for an anti-inflammatory agent. Along with this type of discussion goes the difficulty in explaining to a particular patient that the risk is based on outcomes in populations and that one cannot predict with any certainty what will be the outcome for that particular patient. Nevertheless it is useful to consider that when Australian population figures from the 1990 s are used, there would need to be an increase of only $0.34 \%$ to $0.68 \%$ in the annual death rate from ischaemic heart disease to balance the deaths per annum from NSAID induced upper gastrointestinal events. ${ }^{18}$

\section{CONCLUSION}

The general approach of an ethics committee to provision of information can provide guidance for everyday clinical practice. The prudent action for medical practitioners who wish to prescribe rofecoxib is to simply inform the patient that in the VIGOR study, rofecoxib use was associated with an increased incidence of myocardial infarction which was more than three times greater than that with use of naproxen, another anti-inflammatory drug. This approach does not require a resolution of the contested meaning of results in the various medical journal publications on rofecoxib.

\section{Authors' affiliations}

M J James, L G Cleland, Rheumatology Unit, Royal Adelaide Hospital, Adelaide, SA, Australia

\section{REFERENCES}

1 Merck \& Co. Annual report, 2002. www.merck.com/finance/annualreport/ ar2002/ (accessed 13 Feb 2004).

2 Lexchin J. Should doctors be prescribing new drugs? Int J Risk Safety Med 2002; 15:213-22.

3 CBC disclosure: targeting doctors. www.cbc.ca/disclosure/archives/ 0103_pharm/resources.html (accessed 13 Feb 2004).

4 Bombardier C, Laine L, Reicin A, et al. Comparison of upper gastrointestinal toxicity of rofecoxib and naproxen in patients with rheumatoid arthritis. N Engl J Med 2000;343:1520-8.

5 US Food and Drug Authority. FDA advisory committee briefing document NDA 21-042, s007. VIOXX gastrointestinal safety, 2001. http:// www.fda.gov/ohrms/dockets/ac/01/briefing/3677b2_03_med.pdf (accessed 13 Feb 2004).

6 Mukheriee D, Nissen SE, Topol EJ. Risk of cardiovascular events associated with selective COX-2 inhibitors. JAMA 2001;286:954-9.

7 Konstam MA, Weir MR, Reicin A, et al. Cardiovascular thrombotic events in controlled, clinical trials of rofecoxib. Circulation 2001;104:2280-8.

8 Ray WA, Stein CM, Hall K, et al. Non-steroidal anti-inflammatory drugs and risk of serious coronary heart disease: an observational cohort study. Lancet 2002;359:118-23.

9 Ray WA, Stein CM, Daugherty JR, et al. COX-2 selective non-steroidal antiinflammatory drugs and risk of serious coronary heart disease. Lancet 2002;360:1071-3.

10 Hochberg MC. COX-2: Where are we in 2003? Be strong and resolute: continue to use COX-2 selective inhibitors at recommended dosages in appropriate patients. Arthritis Res Ther 2003;5:28-31.

11 Caughey GE, Cleland LG, Penglis PS, et al. Roles of cyclooxygenase (COX) - 1 and -2 in prostanoid production by human endothelial cells: selective upregulation of prostacyclin synthesis by COX-2. J Immunol 2001;167:2831-8.

12 Caughey GE, Cleland LG, Gamble JR, et al. Upregulation of endothelial cyclooxygenase- 2 and prostanoid synthesis by platelets: role of thromboxane $\mathrm{A}_{2}$. J Biol Chem 2001;276:37839-45.

13 McAdam BF, Catella-Lawson F, Mardini IA, et al. Systemic biosynthesis of prostacyclin by cyclooxygenase (COX)-2: the human pharmacology of a selective inhibitor of COX-2. Proc Natl Acad Sci USA 1999;96:272-7.

14 Catella-Lawson F, McAdam B, Morrison BW, et al. Effects of specific inhibition of cyclooxygenase-2 on sodium balance, hemodynamics, and vasoactive eicosanoids. J Pharmacol Exp Ther 1999;289:735-41.

15 Cheng Y, Austin SC, Rocca B, et al. Role of prostacyclin in the cardiovascular response to thromboxane $A_{2}$. Science 2002;296:539-41.

16 Sidaway $v$ Governors of Bethlem Royal Hospital (1985; AC 871).

17 Rogers $v$ Whittaker (1992; 175 CLR 479).

18 Cleland LG, James MJ, Stamp LK, et al. COX-2 inhibition and thrombotic tendency: a need for surveillance. Med J Aust 2001;175:214-7. 